\title{
Study on System of Network Art Design Based on Web
}

\author{
Shuang Li \\ Hebei Vocational \& Technical College of Building Materials, Qinhuangdao, 066004, China \\ 1162054qq.com
}

Keywords: Computer network, Art design, Network communication, Network art, Digitization

\begin{abstract}
Along with the information era, network of computer has become an important carrier of obtaining information, disseminating culture and communicating thoughts for human. Driven by this tendency, the network art design is showing its vitality and energy; also, art design belongs to the traditional class is brought to a networked transform, which raised the curtain of digital network. The powerful functions, aided design, electronic data and information processing, which belong to the computer produce new and comprehensive art designs under technologies of high-simulation, multi-media, virtual, fractal, etc. They have become new creating method for network art. In the meantime, constantly progressing computer networking technology changes the mode of thinking because of the openness, immediacy, sharing and interactivity of network. This sufficiently reveals a brand new situation of digital information, network sharing and creative design interacting and developing together.
\end{abstract}

\section{Introduction}

Harmonious development of computer network and art design improves the efficiency of disseminating internet information, from the point of science and art; it also arouses an unprecedented creativeness of art interaction in three fields, industrial design, graphic design and digital design. Meanwhile, the thought of digital art design is changing accompanying with the transmission of network. Various art designs that rely on media are changing and zooming to transform to comprehensive network art, which forms a situation of digital technology dominating the innovative field of art design.

\section{The concept and characteristics of digital network art}

Human's living style has an extraordinary change and a brand new one because of digitalization, networking and informatization. Being digital is firstly put forward by an America computer scientist, Nicholas Negroponte, in his book, Being Digital. According to his explanation, the network era of "being digital" and the art of symbolic universe that being constructed by human have realized the trend from differentiation and dissimilation to reverted unite. In the space, human apply digital technology to engage in information spreading, design, communication, etc; also, the human rely on the network spread them to the world quickly. This is called being digital. The basic conception, trend and application of digitalization expound information and network's impacts and value on the era and art design.

Network art is an artistic style, taking computer network as principle intermedia and based on the digital technology to transmitting online. The art through digitalization possesses the characteristic of network media because it uses web as the carrier and exists as hypertext and it absorbs various art element to construct the digitalization. Therefore, the new generated technology makes the network art present the characteristics of openness, integration, freedom, globalization and interactivity. (Fig.1) 


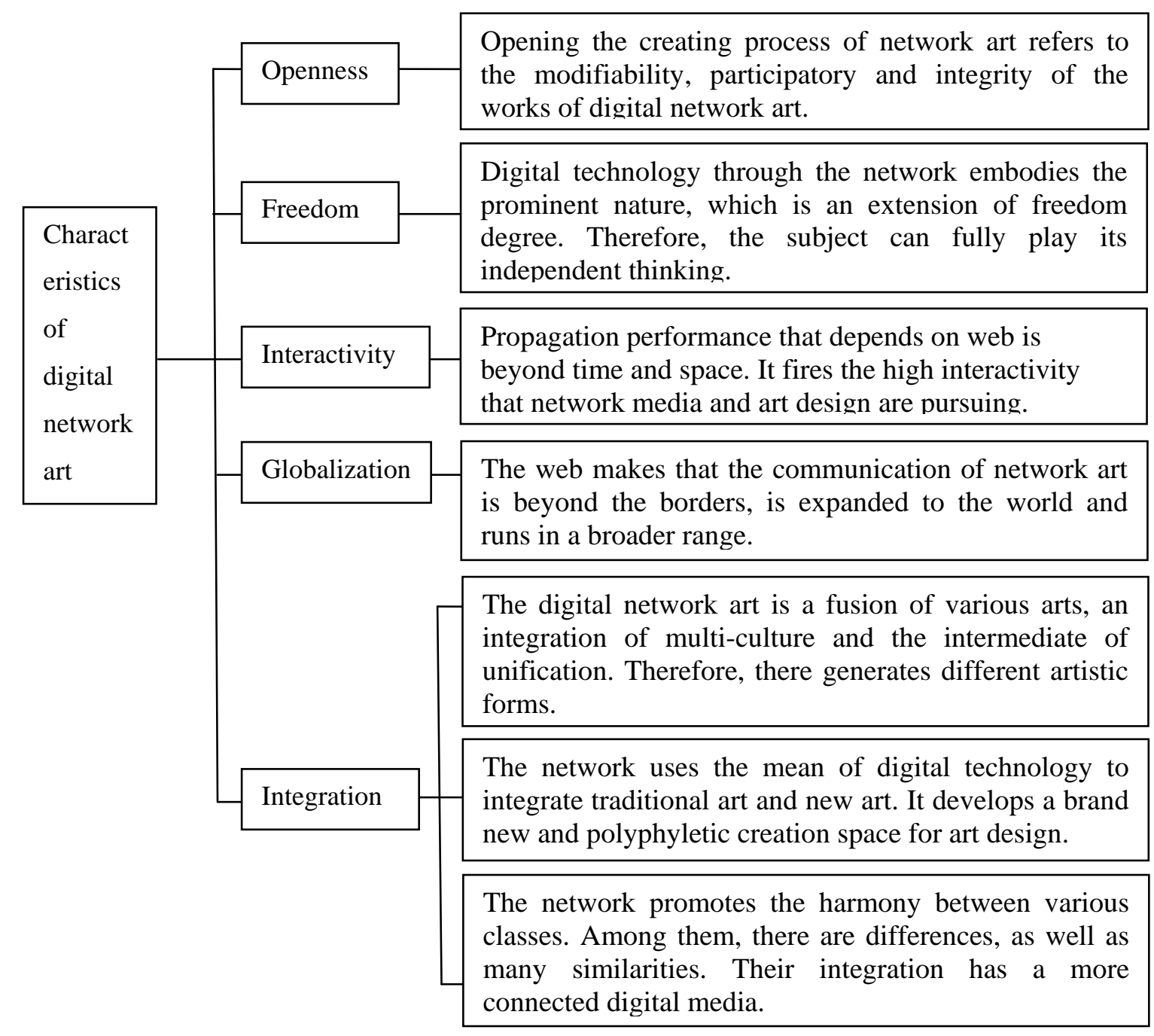

Fig 1 Characteristics of digital network art

The network not only means a new carrier to art, its most important meaning is its characteristics of digital technique. When it extends the degree of freedom and selectivity of art, it also changes the integration of various art elements. In addition, the network endows the new design class the characteristic of integration of technique and art. There is interface of integrated hyperlink and various hiding in the language of network art. This interface digests the wide gap between creation and accept, which is significant to the creative direction of art design.

\section{Revolution of digital network of art design}

Art, as a culture symbol, has a long history and has a variety of kinds, and it is deriving new classed constantly. In Yang Enhuan's Art, he classifies network art into two categories: the traditional artistic class transformed from digital network and new comprehensive network art sublimed from digital art. Relied on the medium, digital code, the network art realized the unification of art beyond physical state and of digital network. Besides, according to the characteristic of multiple coexistence of the information society, the network art presents its more pluralism, diversity and varied styles than the traditional artistic classes. All kinds of network art develops independently and dispersedly. They unify, differentiate and revert with various artistic media materials to more comprehensive network art design. According to the method of classifying art in Art, the systems of network art design can be divided into 5 classes of art: network audition, network multimedia, animation, cartoon, and games of network, fractal and networked virtual reality. (Table.1) 
Table 1 The classification and property analysis of systems of network art design

\begin{tabular}{|c|c|}
\hline Class & Property \\
\hline Network audition & $\begin{array}{l}\text { The art of network audition is created by corresponding medias, including using } \\
\text { video technology and digital network to transform photography, painting, movie, } \\
\text { television, etc. to network audition art. The digitalization of this art can make the } \\
\text { visual arts be preserved non-lossy forever. With the transmitting means of digital } \\
\text { media, adjusting tone and temple freely, transmitting and playing the art widely } \\
\text { and immediately through the network, it reveals a brand new audition art form. }\end{array}$ \\
\hline $\begin{array}{l}\text { Animation and } \\
\text { games of network }\end{array}$ & $\begin{array}{l}\text { Animation and games of network are created by combining flash software, html } \\
\text { language, multimedia, etc. Besides, they are transmitted and developed } \\
\text { three-dimensionally through the network. Since the abundant perform method } \\
\text { and interactivity, the class of design of animation and games of network } \\
\text { becomes a comprehensive artistic class. }\end{array}$ \\
\hline $\begin{array}{l}\text { Network } \\
\text { multimedia }\end{array}$ & $\begin{array}{l}\text { Since computer can intensively process, store and transfer various kinds of } \\
\text { information, like text, graph, sound, video, etc., it has the function of many } \\
\text { media in expressing and transmitting the information. Network multimedia } \\
\text { realizes its transmission in html language. Modular html language constructs } \\
\text { webpage with component mode and the webpage constitutes the website. Then, } \\
\text { the websites combine to the internet. This is the implementation of fractal } \\
\text { self-similar and self-organization generation principles, which have become the } \\
\text { main mean to construct websites. }\end{array}$ \\
\hline Fractal & $\begin{array}{l}\text { Fractal art is the representation of human and computer creating art together in } \\
\text { development stage of digital art. Fractal images are artistic graphics of } \\
\text { Mandelbrot gather and Julia gather based on computer's repeatedly complex } \\
\text { variables iterative operating. Through computer simulation technology and the } \\
\text { technology of virtual reality, fractal art integrating with other network arts to } \\
\text { create and express, which has become the most representative of the art of } \\
\text { computer algorithm. }\end{array}$ \\
\hline $\begin{array}{l}\text { Networked virtual } \\
\text { reality }\end{array}$ & $\begin{array}{l}\text { Networked virtual reality is the art of highly integrating and developing art and } \\
\text { technology. Virtual reality relies on the network, which processes and saves the } \\
\text { imagined art image to construct the virtual reality under network coverage. At } \\
\text { present, the network world has become the largest virtual reality and the art of } \\
\text { virtual reality has gradually become reality. }\end{array}$ \\
\hline
\end{tabular}

When examines the evolution of art, we can see that along with gradually progressed computer network and communicative carrier, the classes of art design are becoming more and more thriving and prosperous. The degree of freedom us is broadened a lot. For example, this interactivity is more obvious in some computer games. People can enter the virtual reality with some specific devices and complete the preset program by changing material, program setting and reading mode. In this kind of network art, virtual world and reality mingle; unlimitedness of creation and reading has a symbiotic relation. It enlarges the extent of freedom of art, which breaches the imprisonment of traditional design concept. From this point, network art changes the rules of traditional art indeed, not only on the content, but also on the form. Finally, it will inspire the art design to have a re-assessment and new exploring on itself in the evolution of digital network.

\section{Application of post-web of internet era on art design}

The network art has been going through the era of early and mid-term network art and it takes the one of mid-term as the symbol of progress. In this era, network art has more freedom than traditional art. It uses digital creation to provide wide degree of freedom in the early time. Therefore, there exists interactivity. However, this interactivity has certain limits in design and creation. In the mid and late 1980s, network art stepped into its main development stage, post-web art time. "Post-web" is not corresponding to a certain concept of time, but to an ideology of symbiotic with 
internet, which is a way of network thinking. It is a form of traditional media art, staying in network media, such as network literature, network drama opera, network music, network art, network movies, network broadcasting, network television, as well as the new art classes with the property of network media, like computer game, web shows, etc. Therefore, when the art of post-wed is penetrated into arts of various kinds, there forms a more advanced new component for network art.

In the design of network art, "post-web" tends to refer to the creative consciousness. This thinking is throughout the whole process of art creating and accepting, including the production of original creative ideas, the process of creating the art and the audience's understanding and accepting of the art. For example, the art of network movie and television is comprehensively integrating text, graph, image, sound and even feeling to present information with various modes of information combination, thus there generates a display of that various information lead to present different procedures and structures. This is the expansion of multi-objectives, multiple path and multi-layer of post web in art creating. Therefore, post-web art requires netted thinking method and the thinking of image thinking and innovation, so that the highest value contained in art design can be perceived to capacity.

\section{Conclusions}

Depending on the digital processing of computer technology, art design takes art forms of various classes as the components of comprehensive art. It transmits beyond time and space by network, which generates various new artistic forms and forms accommodating each other through the cycle of creating, appreciating, assessing and re-creating of network art in interactive process. It only changes the thinking mode of art design, but also makes art evolves to comprehensive network art, supporting by computer network technique. Then, it becomes the dominant method of design and becomes truly independent.

\section{References}

[1] S.D.Li: An introduction to Digital Media Arts,( Tsinghua University Press, In Chinese 2006)

[2] E.H.Yang, B.S.Mie:Art,(People's Publishing House, In Chinese 2001)

[3] H.L.Shi, C.G.Wang: Education of Network Art,(People's Publishing House, In Chinese 2008)

[4] Y.X.Zhang: New Media Art,(Science Press, In Chinese 2005)

[5] Q.Wang: The development of network art in our country in recent years, http://www.studa.net/ 